\title{
The Impact of Mortgages, House Prices and Rents on Household Consumption in the Czech Republic
}

\author{
Rastislav Seč and Petr Zemčík ${ }^{\dagger}$ \\ CERGE-EI ${ }^{\ddagger}$
}

June 2007

\begin{abstract}
We empirically investigate the effect of changes in mortgage payments, housing prices and rents on consumption in the Czech Republic. We combine household expenditure survey data with regional data on apartment prices, which results in a unique microlevel dataset. We find that higher real estate prices result in a consumption increase for apartment owners; higher rents imply a consumption reduction for renters.
\end{abstract}

JEL CLASSIFICATION: R21 - Housing Demand; R31 - Housing Supply and Markets; C33 - Models with Panel Data.

KEY WORDS: panel data, house prices, rents, mortgage, consumption

*I am grateful to Ivan Rybár for helpful comments and suggestions.

${ }^{\dagger}$ For correspondence contact Petr Zemčík, Assistant Professor, CERGE-EI, Charles University, Politických věznu 7, 11121 Prague, Czech Republic, Tel: +420 224005 154, E-mail: petr.zemcik@cerge-ei.cz.

${ }^{\ddagger}$ CERGE-EI is a joint workplace of the Center for Economic Research and Graduate Education, Charles University, and the Economics Institute of the Academy of Sciences of the Czech Republic. 


\section{Introduction}

The economists' attention has been recently attracted to housing market. Some markets show signs of a bubble whose collapse may put an economy into recession. Therefore, it is of interest to study the link between households' consumption on the one hand, and housing prices, rents and mortgages on the other. This relationship has been documented by Case, Quigley, and Shiller (2005), Campbell and Cocco (2005), Slacalek (2006), and others. We empirically investigate how changes in housing prices, rents and mortgages affect households' consumption in the Czech Republic. We quantify the housing wealth effect based on the household level data.

Case, Quigley, and Shiller (2005) use different econometric models for two different datasets, in order to show how housing market wealth and financial wealth affects consumption. Surprisingly, for some model specifications, the authors find weak evidence of a stock market wealth effect, but they confirm strong relationship between housing wealth and consumption. Nonetheless, their results differ across specifications and datasets. Thus the authors do not reach a definitive conclusion. Campbell and Cocco (2005) construct a pseudo panel for regional cohorts for the UK. They investigate housing wealth effect with different regression specifications. Contrary to Case, Quigley, and Shiller (2005), they do not find enough evidence for the housing wealth effect. Similarly to Case, Quigley, and Shiller (2005), Slacalek (2006) constructs a panel for 16 countries and investigate the impact of changes in housing prices and prices of financial assets on consumption. The author finds strong support for housing wealth effect, especially for the Anglo-Saxon economies,

but not for the European countries. Furthermore, Slacalek (2006) confirms the finding of Case, Quigley, and Shiller (2005) that financial wealth effect on consumption is moderate as compared to the housing wealth effect.

We conduct our empirical investigation using a sample of Czech households. There 
are two reasons why we investigate the effect for the Czech economy. To the best of our knowledge this is the first study that exploits the housing wealth effect for a former transition economy. Our data set captures households' behavior on micro level. Campbell and Cocco (2006) who use regional cohorts to estimate the housing wealth effect are a good example of a study that relies on semi-micro level data. Slacalek (2006) and Case, Quigley, and Shiller (2005) use a panel dataset for 16 countries. In addition, Case, Quigley, and Shiller (2005) also construct panel dataset for the US households and estimate the housing wealth effect on individual level. Since our estimates are based on household level data, our results are more precise than results based on aggregated or partially aggregated data. The mortgage market in the Czech Republic was established only in 1996 and underwent a large expansion in terms of aggregate volume of mortgages. According to the Czech National Bank the nominal mortgage volume increased by factor 11 for our sample period 2001-2005. Also, the housing price, rent, mortgage payment, household's consumption and household's labor income varies considerably across households and over time as well. The variation of the key variables allows us to identify the housing wealth effect at the individual level. Since our aim is to separate the partial effect of housing price, rent and mortgage from other sources of variation, we also control for other changes in labor income and other individual household's characteristics attributes.

We use the Household Expenditure and Consumption survey of the Czech Statistical Office (CSU) that captures approximately 3000 Czech households from 1991 up to 2006. We combine it with a panel from the Institute for Regional Information at Brno (IRI) that consists of apartment prices and rents for 335 regions from 2001 to 2005 . Using this combined dataset we estimate the housing wealth effect. We explicitly distinguish between homeowners and renters and mortgage payers and non-mortgage payers. We find that both the housing price and rent have significant impact on consumption, but changes in mortgage payment do not. With respect to our results, we find that increase in the housing rent increases 
homeowner's consumption, but induces a consumption decrease for a renter. On the other hand, increase in the housing price increases homeowner's consumption and has no impact on renters consumption.

This paper is organized as follows. In the second section, we describe in detail both surveys and the strategy we use to construct our dataset. In the third section we describe the estimation method we use to estimate the housing wealth effect and we discuss our results. Finally, we summarize our results and discuss the significance of the partial effects of housing prices, rents and mortgages on consumption.

\section{Data description}

We combine two main data sources to construct our dataset that we use to estimate the effect of changes in the housing prices, housing rents and mortgages on consumption. Namely, the Household Consumption and Expenditure survey of the Czech Statistical Office (CSU) and the data set of the Institute of Regional Information at Brno (IRI). Adjustment to inflation is calculated using the CPI reported by the Czech National Bank (CNB).

The CSU data set captures different households' expenses on goods and services, different sources of income, and households' specific characteristics. Since we do not use all the information available, we do not describe the whole structure of the data set. The survey of the CSU uniquely identifies households by a household specific id and county (okres) of origin. Our sample covers all 76 counties of the Czech Republic. For each of the available household in our sample we compute non-durable consumption and labor income. Also, the survey of the CSU contains other variables for which we control in our econometric model. We include into our sample variables such as the household's reported mortgage payment, the reported size of the apartment, the reported household's head age, the reported household's size, reported number of children, region (kraj) and county (okres) of the household's origin, the 
housing ownership status and type of dwelling which is either an apartment or a house. The CSU denotes the type of housing by variable $d u m$ (dwelling) that takes values $\{1,2,3,4,5,6\}$, where 6 denotes a house. We include into our sample only those households for which di̊m $\neq 6$. We infer about the housing ownership status from the variable byt that takes values $\{1,2,3,4\}$, where 1 means that the household rents the apartment and values $2,3,4$ denote different forms of private ownership. Specifically, the variable byt equals 2 if the household is a member of a real estate cooperative (družstvo), in the case when the variable byt takes value 3 the household owns the dwelling, and whenever the variable byt is equal to 4 the household owns the whole building. Based on the CSU data we define two dummy variables. DMP stands for Dummy Mortgage Payment and DR stands for Dummy Renting. D $R_{i, t}$ is unity if the household rents apartment and zero otherwise. $D M P_{i, t}$ is defined to be equal to one if the household pays mortgage and zero otherwise. Using the above mentioned variables we construct our dataset which is merged with the adjusted housing price/rent panel provided by the IRI.

The IRI's data set contains housing prices and rents for 335 regions from 2001 up to 2005. Both housing prices and rents are based on hedonic regressions. The housing price and rent expresses price or rent for $1 \mathrm{~m}^{2}$ for the standardized $68 \mathrm{~m}^{2}$ apartment. Since the IRI and CSU definition of region is not identical, we construct a measure for the apartment price and the apartment rent for each county. Our measure of housing price is an average of regional prices of a standardized $68 \mathrm{~m}^{2}$ apartment in a given county. Similarly, we define the apartment rental price as the advertised average of regional rents in a given county. ${ }^{1}$

We multiply each measure of apartment price and rent by the the reported housing size in $m^{2}$ and calculate the apartment price and rent. The IRI housing price and rent survey captures only the period between 2001 and 2005, hence our investigation is based only on

\footnotetext{
${ }^{1}$ The IRI does not distinguish among 18 Prague districts. Therefore, we use the same apartment price and apartment rent for all households living in the 18 Prague districts.
} 
this period. Finally, we transform all nominal values into real values by using the CPI and compute first differences for all variables. We provide basic statistics for each of the computed and transformed variables in Table ??.

We have more than 1000 observations for each time period. The cross sectional average of growth for the real income $\log \left(y_{i, t}\right)$ steadily increases from 2001 up to 2004 and the growth for 2005 is slightly smaller than the growth in 2004. On the other hand, average growth of consumption $\overline{\Delta \log \left(c_{t}\right)}$ is not increasing over time and instead exhibits oscillations. The average of the real mortgage payment growth does not exhibit any particular pattern and varies over time and decreases somewhat in 2004. The average real price steadily increases over time, but similarly to the average real labor income the growth slows down in 2005. Real rents follow the same pattern displayed by housing prices, with somewhat smaller growth rate. Note that the real mortgage payment growth is the most volatile variable in our dataset.

Finally, using the household's county of origin we merge the CSU dataset with the IRI dataset. The dataset contains information about household consumption, labor income, size of the apartment, ownership status, our measure of housing price and rent for household's county of origin, household's mortgage payment, household's head age, household size and number of children for the time period between 2001 and 2005.

\section{The Econometric Model}

In the following section, we describe the econometric model that we use to estimate the wealth effect of the housing price, rent and mortgage payment on consumption. The estimation

closely follows Cambell and Cocco (2006). While Campbell and Cocco (2006) focus on regional cohorts, we focus on individual level data and estimate the housing wealth effect for the households.

We expect that the household's decisions are affected by whether they own their apart- 
ment and whether they pay a mortgage for the apartment. We therefore explicitly distinguish between homeowners and renters in our regression model. Similarly, we distinguish between households with mortgage and households without mortgage. This approach highlights the difference between the housing wealth effect for both homeowners and renters as well as for mortgage-payers and non-payers. Our intuition can be rationalized as follows. An increase in mortgage payments decreases consumption of the homeowner, since mortgage payment is a part of the housing costs. On the other hand, increasing the mortgage payment will also induce a decrease in consumption for the renter, since the renter is likely to increase savings to acquire an apartment in the future. Also, we can expect that the homeowner and the renter will respond differently to a housing price change. Suppose that the housing price appreciates, then the homeowner increases her consumption, but the renter decreases her consumption, again to save more for the future apartment purchase. If we consider an increase in rents, the renter decreases her consumption. The homeowner, contrary to the renter, responds differently since the housing rent is a part of the opportunity cost of housing. Likewise, the wealth effect differs for households with mortgage and households without mortgage payment. If the household is a mortgage payer it will respond to changes in mortgage payments, but non-paying household will not, since non-paying household does not need to adjust for the mortgage payment increase. Therefore, the wealth effect of change of the housing price, rent and mortgage payment differs for renters as opposed to homeowners and mortgage payers as opposed to non-payers.

The difference in the size of the wealth effect is captured by previously defined dummy variables $D R_{i, t}$ and $D M P_{i, t}$. All possible combinations of explanatory variables and previously defined dummies are considered as well. In addition, we provide sample shares of homeowners/renters and mortgage payers/non-payers in Table ??. The majority of the sample households $49 \%$ owns apartment and does not pay mortgage. These households either bought their apartment or are members of real estate cooperatives. On the other hand, 
only $11 \%$ of our sample population pays mortgage payments and owns an apartment. These households either live in a newly constructed apartment or borrowed to buy the apartment. The share of renters without mortgage accounts for $34 \%$ of all observations. The renters who pay mortgage account for only $5 \%$ of all households. The fact that a renter pays mortgage may be seen as dubious. Nonetheless, we argue that there is an explanation that rationalizes renter's behavior. The renter can pay mortgage while waiting for the apartment to be finished, and thus her status of a renter will change in the future. We also consider interaction dummies and all possible combination with other explanatory variables. Note that the interaction term $D R_{i, t} \times D M P_{i, t}$ equals one only for households who do not pay mortgage and own apartment which is $5 \%$ of overall population. Since the interaction terms are insignificant we do not consider them in our baseline regression model.

Recall that the CSU data set, which we use to compute labor income and non-durable consumption is constructed so that it matches the Czech household income distribution. However, our estimation results are not subject to the sample selection bias, since we use income as an explanatory variable. Note that we use mortgage payment, housing price and rent as explanatory variables, and thus the estimation may suffer from endogeneity, since equilibrium relationship may tie these variables together.

We estimate the following regression model:

$$
\begin{aligned}
& \Delta \log \left(c_{i, t}\right)=\alpha+\beta_{0} D R_{i, t}+\beta_{1} D M P_{i, t}+\beta_{2} \Delta \log \left(y_{i, t}\right)+\beta_{3} D R_{i, t} \Delta \log \left(y_{i, t}\right)+\beta_{4} D M P_{i, t} \Delta \log \left(y_{i, t}\right)+ \\
& \beta_{5} \Delta \log \left(m_{i, t}\right)+\beta_{6} D R_{i, t} \Delta \log \left(m_{i, t}\right)+\beta_{7} D M P_{i, t} \Delta \log \left(m_{i, t}\right)+\beta_{8} \Delta \log \left(p_{i, t}\right)+\beta_{9} D R_{i, t} \Delta \log \left(p_{i, t}\right)+ \\
& \beta_{10} D M P_{i, t} \Delta \log \left(p_{i, t}\right)+\beta_{11} \Delta \log \left(r_{i, t-1}\right)+\beta_{12} D R_{i, t} \Delta D R_{i, t} \Delta \log \left(r_{i, t-1}\right)+\Delta \log \left(r_{i, t-1}\right)+\gamma^{T} X_{i, t}
\end{aligned}
$$

where $i$ denotes household, $t$ denotes time, $c$ stands for consumption, $y$ denotes income, $p$ denotes housing price, $m$ denotes mortgage payment and $r$ denotes housing rental price. For each $i$ we compute first differences for all variables if we have two subsequent observations. 
All the variables are transformed from nominal to real terms. In particular, for each $z$ and any $i, t$ and $t-1$ we compute $\Delta \log \left(z_{i, t} / C P I_{t}\right)=\log \left(Z_{i, t} / C P I_{t}\right)-\log \left(Z_{i, t-1} / C P I_{t-1}\right)$. We include also household specific demographic characteristics such as household's age, household's size and number of children, time trend or dummies for region of origin, which we denote as $X_{i, t}$. Note that we use $\Delta \log \left(r_{i, t-1}\right)$ in our regression model variable rather than $\Delta \log \left(r_{i, t}\right)$ variable, what stems from the fact that housing rental contracts are long term contracts, and therefore the household anticipates past values of rents and not the present.

The constructed sample is an unbalanced panel. We pool all of our observations and estimate several versions of our baseline model by OLS. Each of the estimated models we assume different specification for $X_{i, t}$. The results for all of the estimated versions of our model are reported in Table ??. For the first estimation we do not allow for household specific demographic characteristics or for time trend or dummies for region of origin, which implies that $X_{i, t}=0$. For the second version of the estimated model we do control for household specific demographic characteristics, and include $\gamma^{T} X_{i, t}=$ $\gamma_{1} \times$ HouseholdHeadAge $_{i, t}+\gamma_{2} \times$ HouseholdSize $_{i, t}+\gamma_{3} \times$ NumberofChildren $_{i, t}$ in the regression. The third estimated version of our model includes a time trend, in particular $\gamma^{T} X_{i, t}=\gamma_{4} \times$ time. We also control for the household's region of origin, but since the household's region of origin does not explain any variation in consumption we do not report the results for this version of our model. For each of the estimated models we test for the joint impact of $X_{i, t}$, and provide the $\mathrm{F}$ statistics and the p-value for the test. Notice that $\gamma^{T}$ is significant only when $X_{i, t}$ includes household specific demographic characteristics. In any case, considering the household specific demographic characteristics does not change quantitatively and qualitatively estimation results for coefficients of interest. Hence, we comment only on the results of our regression model where we do not control for any variation in $X_{i, t}$. We find that homeowners respond differently to changes in house prices and rents than renters. For renters a $1 \%$ increase in rents decreases consumption by $0.25 \%$ as compared 
with homeowner. Higher house prices imply greater consumption growth for homeowners but not for renters. We find also that neither homeowners nor renters react to changes in mortgage payments. Similarly, once the household pays a mortgage, responses to changes in housing prices, rents and mortgages are not significantly different as opposed to a non-paying household.

\section{Summary}

We present a preliminary study of the housing wealth effect for Czech households. We use Consumption and Expenditure survey of the CSU and the Apartment prices and rents survey of the IRI to construct dataset that captures approximately 3000 households over 5 years from 2001 up to 2005. We use the information on housing ownership and the information on mortgage payment to estimate differences in the housing wealth effect components for homeowners and renters and mortgage payers and non-payers.

Specifically, we estimate the impact of change in housing prices, rents and mortgage payments on consumption. We find that mortgage payment does not explain any variation in consumption. In particular, we find that renter's adjustment of consumption as a response to change in housing prices and rents significantly differs from the adjustment of the homeowner.

In our future research we will focus on improvements of the econometric methodology. We plan to enrich it in two ways. First, note that we use model in first differences and estimate the coefficients by pooled OLS. The model in first differences can be replaced by a fixed-effect model with an autocorrelated error structure which can be estimated using levels rather than first differences. This approach can yield more significant results, since there is no need to have two subsequent observations for a household, and thus we will make better use of all available information. The second fruitful extension of our current methodology addresses the problem of potential endogeneity in our model. Endogeneity may be a problem 
since equilibrium relationship ties housing price and rent together. Moreover, we can view the real mortgage payment as an endogenous variable as well. We will use a 2SLS approach to account for the potential endogeneity. The key to this approach will be identification of suitable instrumental variable. 


\section{References}

Case, K.E., Quigley, J., and Shiller, R.J., (2005). "Comparing Wealth Advances in Macroeconomics 1(5), 1235-1235.

Campbell, J.Y., and Cocco, J.F., (2005). "How Do House Prices Affect Consumption? Evidence From Micro Data," Harvard Institute of Economic Research Discussion Paper Number 2083.

Slacalek, J., (2005). "What Drives Personal Consumption? : The Role of Housing and Financial Wealth," Harvard Institute of Economic Research Discussion Paper Number 2083 
Table 1: Basic Descriptive Statistics

\begin{tabular}{|c|c|c|c|c|c|}
\hline & & \multicolumn{4}{|c|}{ year } \\
\hline & & 2002 & 2003 & 2004 & 2005 \\
\hline \multirow{4}{*}{$\Delta \log \left(y_{i, t}\right)$} & observations & 1123 & 1050 & 1096 & 1010 \\
\hline & Mean & .01 & .035 & .042 & .029 \\
\hline & Standard Deviation & .324 & .316 & .365 & .299 \\
\hline & Minimum & -4.292 & -2.352 & -3.446 & -2.29 \\
\hline \multirow{4}{*}{$\Delta \log \left(c_{i, t}\right)$} & Maximum & 1.741 & 1.347 & 2.982 & 2.211 \\
\hline & Mean & .012 & .002 & .033 & -.002 \\
\hline & Standard Deviation & .251 & .274 & .285 & .238 \\
\hline & Minimum & -1.803 & -2.047 & -1.562 & -1.815 \\
\hline \multirow{4}{*}{$\Delta \log \left(m_{i, t}\right)$} & Maximum & 1.502 & 1.294 & 2.152 & 1.837 \\
\hline & Mean & .008 & .122 & -.027 & .006 \\
\hline & Standard Deviation & 2.217 & 2.271 & 2.112 & 1.822 \\
\hline & Minimum & -11.586 & -11.207 & -10.796 & -11.424 \\
\hline \multirow{4}{*}{$\Delta \log \left(r_{i, t}\right)$} & Maximum & 11.207 & 13.097 & 10.958 & 11.754 \\
\hline & Mean & .032 & .118 & .078 & .011 \\
\hline & Standard Deviation & .104 & .052 & .098 & .107 \\
\hline & Minimum & -1.161 & -.444 & -1.03 & -.805 \\
\hline \multirow{5}{*}{$\Delta \log \left(p_{i, t}\right)$} & Maximum & 1.718 & .656 & 1.522 & 1.119 \\
\hline & Mean & .054 & .17 & .132 & .044 \\
\hline & Standard Deviation & .114 & .062 & .114 & .127 \\
\hline & Minimum & -1.158 & -.365 & -.931 & -.861 \\
\hline & Maximum & 1.728 & .675 & 1.569 & 1.202 \\
\hline
\end{tabular}

Where $y$ denotes real income, $c$ denote real consumption, $m$ denotes real mortgage payment, $r$ denotes real housing rent and $p$ denotes real housing price 
Table 2: Sample Population Distribution

Sample Poulation Distribution for

\begin{tabular}{ccc}
\multicolumn{3}{c}{ Owners/Renters and Mortgage Payers/Non-Payers } \\
\hline \hline & $D M P=0$ & $D M P=1$ \\
$D R=0$ & $49.11 \%$ & $11.55 \%$ \\
$D R=1$ & $34.32 \%$ & $5.02 \%$ \\
\hline
\end{tabular}

Where $D R=1$ denotes renting and $D M P=1$ denotes paying mortgage 
Table 3: Estimation results

Dependent variable $\Delta \log \left(c_{i, t}\right)$

\begin{tabular}{|c|c|c|c|}
\hline Variable & $\begin{array}{r}\text { Estimates } \\
\text { (Std. Err.) }\end{array}$ & $\begin{array}{r}\text { Estimates } \\
\text { (Std. Err.) }\end{array}$ & $\begin{array}{r}\text { Estimates } \\
\text { (Std. Err.) }\end{array}$ \\
\hline$\Delta \log (y)$ & $0.504^{* * *}$ & $0.506^{* * *}$ & $0.504^{* * *}$ \\
\hline & $(0.019)$ & $(0.019)$ & $(0.019)$ \\
\hline$D R \times \Delta \log (y)$ & $\begin{array}{l}-0.140^{* * *} \\
(0.027)\end{array}$ & $\begin{array}{l}-0.142^{* * *} \\
(0.027)\end{array}$ & $\begin{array}{l}-0.141^{* * *} \\
(0.027)\end{array}$ \\
\hline$D M P \times \Delta \log (y)$ & 0.028 & 0.024 & 0.030 \\
\hline & $(0.038)$ & $(0.038)$ & $(0.038)$ \\
\hline$\Delta \log (m)$ & -0.002 & -0.002 & -0.002 \\
\hline$D R \times \Delta \log (m)$ & $\begin{array}{r}(0.003) \\
0.000\end{array}$ & $\begin{array}{r}(0.003) \\
0.001\end{array}$ & $\begin{array}{r}(0.003) \\
0.000\end{array}$ \\
\hline & $(0.004)$ & $(0.004)$ & $(0.004)$ \\
\hline$D M P \times \Delta \log (m)$ & 0.006 & 0.005 & 0.006 \\
\hline & $(0.004)$ & $(0.004)$ & $(0.004)$ \\
\hline$\Delta_{t-1} \log (r)$ & $\begin{array}{r}0.077 \\
(0.066)\end{array}$ & $\begin{array}{r}0.078 \\
(0.066)\end{array}$ & $\begin{array}{r}0.055 \\
(0.067)\end{array}$ \\
\hline$D R \times \Delta_{t-1} \log (r)$ & $-0.250^{* * *}$ & $-0.250^{* * *}$ & $-0.247^{* * *}$ \\
\hline$D M P \times \Delta_{t-1} \log (r)$ & $\begin{array}{r}(0.079) \\
0.027 \\
(0.091)\end{array}$ & $\begin{array}{r}(0.079) \\
0.022 \\
(0.091)\end{array}$ & $\begin{array}{r}(0.079) \\
0.040\end{array}$ \\
\hline$\Delta \log (p)$ & $\begin{array}{l}0.126^{* * *} \\
(0.046)\end{array}$ & $\begin{array}{l}0.125^{* * *} \\
(0.046)\end{array}$ & $\begin{array}{l}0.160^{* * *} \\
(0.050)\end{array}$ \\
\hline$D R \times \Delta \log (p)$ & $\begin{array}{l}-0.120^{*} \\
(0.067)\end{array}$ & $\begin{array}{l}-0.117^{*} \\
(0.067)\end{array}$ & $\begin{array}{l}-0.133^{* *} \\
(0.067)\end{array}$ \\
\hline$D M P \times \Delta \log (p)$ & $\begin{array}{l}-0.125 \\
(0.078)\end{array}$ & $\begin{array}{r}-0.122 \\
(0.078)\end{array}$ & $\begin{array}{l}-0.130^{*} \\
(0.078)\end{array}$ \\
\hline$D R$ & $\begin{array}{l}0.036^{* * *} \\
(0.012)\end{array}$ & $\begin{array}{l}0.036^{* * *} \\
(0.012)\end{array}$ & $\begin{array}{l}0.038^{* * *} \\
(0.012)\end{array}$ \\
\hline$D M P$ & $\begin{array}{r}0.007 \\
(0.015)\end{array}$ & $\begin{array}{r}0.008 \\
(0.015)\end{array}$ & $\begin{array}{r}0.007 \\
(0.015)\end{array}$ \\
\hline Household's head age & & $\begin{array}{r}0.000 \\
(0.000)\end{array}$ & \\
\hline Number of persons & & -0.008 & \\
\hline Number of children & & $\begin{array}{l}0.016^{* *} \\
(0.008)\end{array}$ & \\
\hline Trend & & & $\begin{array}{l}0.008^{*} \\
(0.005)\end{array}$ \\
\hline Intercept & $\begin{array}{l}-0.038^{* * *} \\
(0.008)\end{array}$ & $\begin{array}{l}-0.042^{*} \\
(0.022)\end{array}$ & $\begin{array}{l}-0.074^{* * *} \\
(0.023)\end{array}$ \\
\hline$N$ & 2372 & 2372 & 2372 \\
\hline$R^{2}$ & 0.354 & 0.355 & 0.355 \\
\hline & 92.225 & 76.273 & 86.34 \\
\hline Degrees of freedom for $F$ test & $(14,2357)$ & $(15,2356)$ & $(15,2356)$ \\
\hline $\begin{array}{l}\gamma^{T} \text { F-test } \\
\text { Degrees of freedom for F test }\end{array}$ & & $\begin{array}{r}2.66^{* *} \\
(13,2354)\end{array}$ & \\
\hline
\end{tabular}

Significance levels : $\quad *: 10 \% \quad * *: 5 \% \quad * * *: 1 \%$

Where $y$ denotes real income, $c$ denotes real consumption, $m$ denotes real mortgage payment, $r$ denotes real housing rent and $p$ denotes real housing price.

DMP is dummy variable for mortgage payments and DR denotes that household rents apartment. 